\title{
Foreign body presenting as a duodenal mass: Case report and literature review
}

\author{
Catherine W Chung, Zachary J Plummer, Leigh Spera, J oshua Waters, Eugene P Ceppa \\ Department of Surgery, School of Medicine, Indiana University, USA
}

Correspondence: Eugene P Ceppa. Address: Department of Surgery, School of Medicine, Indiana University, USA. Email: eceppa@iupui.edu

Received: September 28, 2015

Accepted: October 25, 2015

Online Published: November 10, 2015

DOI : $10.5430 /$ crim.v2n4p88

URL: http://dx.doi.org/10.5430/crim.v2n4p88

\section{Abstract}

Importance: An abnormal clinical presentation of foreign body ingestion and its therapeutic approach. Review of the literature to determine rate of perforation along the gastrointestinal tract by foreign body ingestion and to identify appropriate diagnosis and treatment of ingested foreign bodies in the duodenum.

Observations: A case report of a 57-year-old female presenting with abdominal pain, chest pain, and headaches for two days. With computed tomography imaging, findings of an intraluminal mass in the duodenum and retroperitoneal air were identified, leading to suspicion of a perforated duodenal malignancy. On endoscopic ultrasound, a toothpick was identified protruding through the wall of the third portion of the duodenum, which was removed by upper endoscopic forceps. A review of the literature yielded 236 cases of foreign body perforation of the gastrointestinal tract between the years 2000 to 2015 in adults 18 years and older. Perforation rate of the small bowel was highest at $39.8 \%$ followed by the duodenum $22 \%$, colon $20.3 \%$, sigmoid $5.5 \%$, and unidentified site $1.7 \%$. Literature analysis for therapeutic options for gastrointestinal injury by foreign body ingestion included endoscopy, laparotomy, or laparoscopy. A diagnostic therapeutic algorithm for duodenal foreign body ingestion was created.

Conclusions: Ingested foreign bodies can present with a variety of clinical symptoms. Thus, they should be considered as part of a differential diagnosis for cases with gastrointestinal symptoms without clear etiology. Even with imaging studies, foreign body ingestion can be difficult to diagnose initially. Sharp objects, especially toothpicks, have an increased rate of perforation of the gastrointestinal tract and have a high associated morbidity and mortality. As such, prompt diagnosis and management are necessary to improve outcomes.

\section{Keywords}

Foreign body, Duodenal mass, Toothpick, Upper endoscopy, Endoscopic ultrasound, Perforation

\section{Introduction}

A duodenal mass discovered upon imaging in a symptomatic patient with abdominal pain exhibits a wide differential diagnosis ${ }^{[1]}$. This includes duodenal malignancy, peptic ulcer disease, secondary malignancy, polyp, foreign body ingestion, hematoma, abscess, gallstone ileus, and annular pancreas ${ }^{[1-3]}$. With the additional finding of pneumoperitoneum, the differential is reduced to duodenal malignancy, peptic ulcer disease, foreign body ingestion, abscess, and 
gallstone ileus ${ }^{[3,4]}$. This report illustrates the workup of such a patient and reviews the diagnostic algorithm for future cases.

\section{Case report}

A 57-year-old obese female presented with acute epigastric pain, chest pain, and headaches for two days. Prior to onset of symptoms, she was clinically well without history of similar symptoms. In the emergency department, the patient's vital signs were within normal limits except for a low grade temperature of $100.2^{\circ} \mathrm{F}$ and a heart rate of 105 . She denied any nausea, vomiting, or recent bowel changes. Physical examination demonstrated a distended, protuberant abdomen with epigastric tenderness and no peritoneal signs. Laboratory analysis was significant for a white blood cell (WBC) count of $11.2 \times 10^{3} / \mu 1$.

Workup included a computed tomography (CT) scan of the abdomen and pelvis with oral and intravenous (IV) contrast, which showed evidence of an intraluminal mass $2.2 \mathrm{~cm} \times 1.4 \mathrm{~cm}$ in the junction of the second and third portion of the duodenum beyond the ampulla. Additionally, there was a tiny focus of extra-luminal air in the retroperitoneum, indicating a contained perforation with surrounding inflammatory changes (see Figure 1). The etiology of the mass at this time was difficult to determine. The diagnoses considered included duodenal malignancy, peptic ulcer disease, foreign body ingestion, abscess, and gallstone ileus.

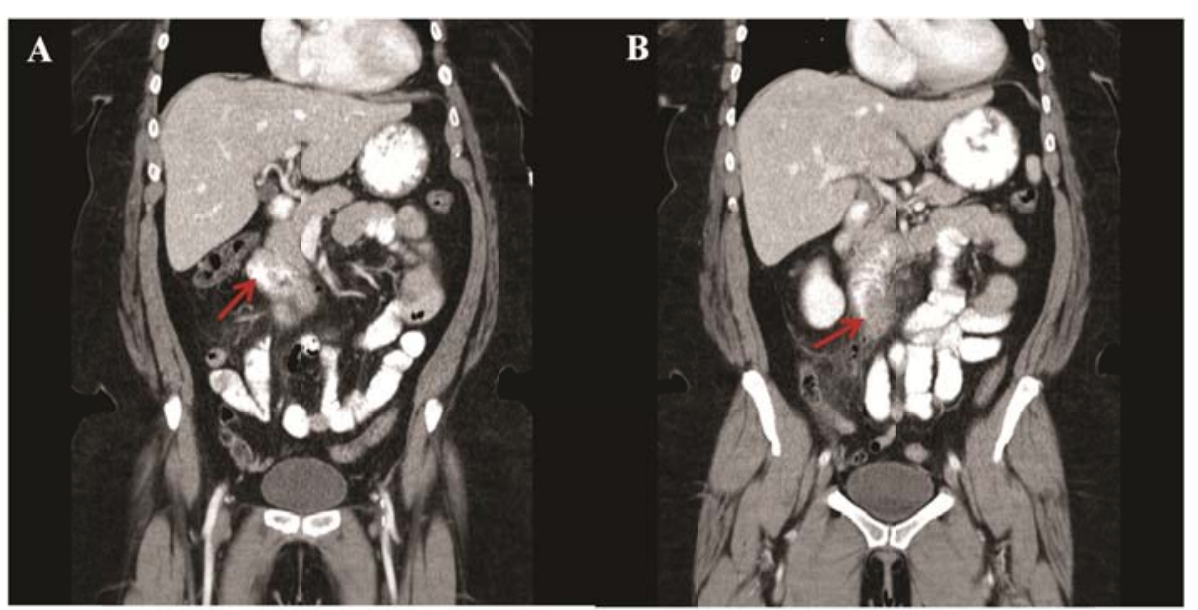

Figure 1. Coronal view of CT scan of the abdomen and pelvis with oral and IV contrast. The red arrows point to the junction of the second and third portion of the duodenum containing the intraluminal mass. Note the surrounding inflammatory changes

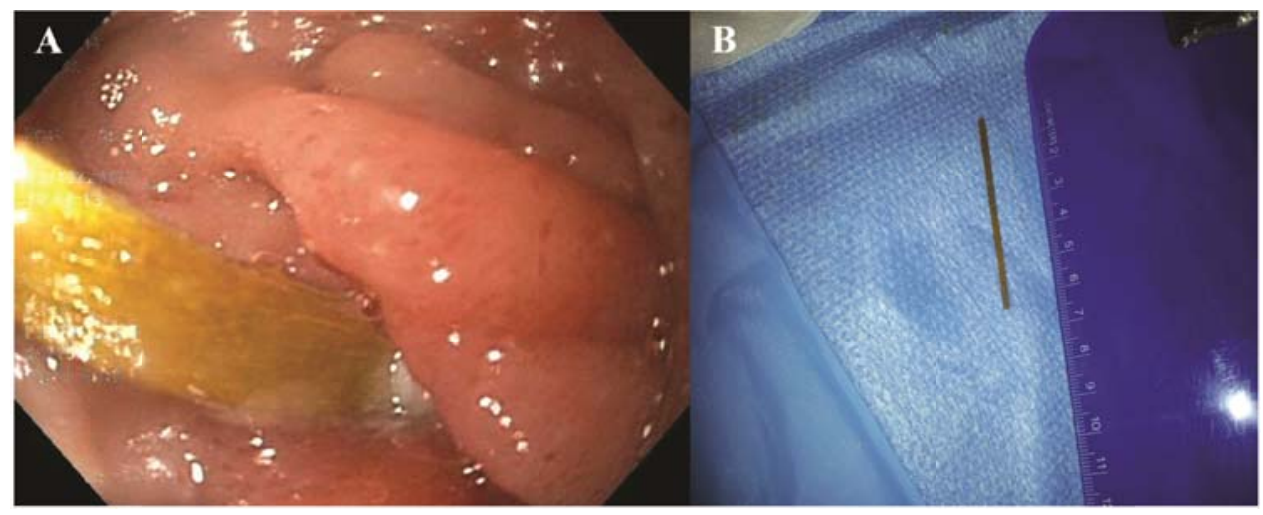

Figure 2. A. Wooden toothpick found penetrating the third portion of the duodenum; B. Endoscopic retrieval of the duodenal perforating wooden toothpick, measuring $6.4 \mathrm{~cm}$ 
Decisions to manage her medically were made. She was admitted to the hospital, started on empiric IV antibiotics, and placed on bowel rest. Tumor markers, blood cultures, and a hepatic functional panel were ordered. Duodenal malignancy was suspected and general surgery was consulted. After seven days with clinical improvement, she underwent an endoscopic ultrasound (EUS) for tissue diagnosis of suspected malignancy. EUS findings showed a foreign body in the third portion of the duodenum. An upper endoscopy was subsequently performed, illustrating a wooden toothpick protruding through the third portion of the duodenal wall with purulence at its base (see Figure 2). The toothpick was removed with regular forceps. Consequently, a small fistula was found in the duodenum, onto which one hemostatic clip was successfully placed. After this procedure, the patient recovered without complications. When asked, the patient recalled using a toothpick to hold her tacos together a month prior to presentation. She was discharged home the following day on a regular diet.

\section{Methods}

A Medline search identified 36 publications containing case reports, providing 236 cases of ingested foreign bodies leading to gastrointestinal (GI) perforation. The search terms used included "foreign bodies" AND "ingestion" AND "intestinal perforation". The search results were limited by "English" and "Humans" and for articles published between 2000 and 2015 on patients who were 18 years old or older. Further review of the literature identified 14 articles that outlined intervention and treatment modalities. Parameters of interest were location of perforation, diagnostic work up, and management options. From reviewing these articles, tables and flowcharts were created.

\section{Results}

Analysis of the 36 Medline articles yielded percent perforation based on anatomical location (see Table 1) ${ }^{[5-40]}$. Foreign body perforation most commonly occurred in the small bowel at a rate of $39.8 \%$, followed by the duodenum $22 \%$, the colon $20.3 \%$, sigmoid colon $5.5 \%$, and un-identified site of peroration occurred at a rate of $1.7 \%$.

Further analysis of 14 articles allowed compilation of a table describing common therapeutic options of GI injuries by foreign bodies according to location (see Table 2) ${ }^{[41-54]}$. For foregut obstruction, the recommendation is rigid or flexible endoscopy, endoscopy vs. laparoscopy/laparotomy with gastrotomy for the stomach, endoscopy vs. laparoscopy/ laparotomy for the duodenum. Small bowel foreign body obstruction is managed by balloon enteroscopy vs. laparoscopy/ laparotomy. Lastly, for large bowel obstruction, laparoscopy/laparotomy is recommended.

\section{Discussion}

Foreign body ingestion is not an uncommon medical phenomenon, but resulting GI injury from ingestion is rare. About $80 \%-90 \%$ of unintentionally ingested foreign bodies pass spontaneously through the GI tract without associated injury. Around $10 \%-20 \%$ of ingestions require endoscopy and only $1 \%$ required surgery ${ }^{[55]}$. The rate of perforation by ingested foreign bodies is reported to be less than $1 \%{ }^{[12]}$. Sharp foreign body ingestions carry perforation rates up to $15 \%-35 \%{ }^{[27]}$. This case report illustrated the difficulty in diagnosis of a foreign body as the source of abdominal pain by history, exam, and CT imaging.

Toothpick ingestion accounts for approximately $9 \%$ of ingested foreign bodies. Perforation of the small bowel by toothpick is rare with an incidence of 0.2 per 100,000 persons annually. It carries a high associated morbidity of $25 \%$ and mortality of $7 \%-18 \%$. Thus, prompting immediate intervention to prevent further injury ${ }^{[32,36,51]}$. However, toothpick ingestion can be difficult to diagnose. Some studies report only $12 \%$ of patients provide a history of ingestion ${ }^{[56]}$. Additionally, a correct preoperative diagnosis was made in only $23 \%$ of patients who ultimately required surgical exploration ${ }^{[32]}$. Definitive diagnosis of toothpick ingestion was made by laparotomy $53 \%$, endoscopy $19 \%$, imaging 
studies $14 \%$, and autopsy $12 \%$ of cases ${ }^{[36]}$. In this case report, the patient had no recollection of toothpick ingestion upon admission and her initial diagnosis was concerning for a duodenal malignancy.

GI tract foreign body perforation occurs at particular locations due to acute angles, reduced caliber of bowel lumen, and transitions from a mobile (ileum and sigmoid) to a relatively fixed portion of bowel (cecum and rectum) ${ }^{[37]}$. Susceptible locations include the pylorus, duodenal C-loop, ileocecal valve, hepatic flexure, splenic flexure, ileocecal valve, sigmoid colon, and rectum. Based on Table 1, duodenal perforation rate was high at $22.0 \%$, although less common than jejunal and ileal perforations rates of $39.8 \%$. Once perforation occurs, the patient is at risk for intraabdominal sepsis, likely the most common morbidity resulting in mortality ${ }^{[50]}$. The critical imaging finding of perforation is pneumoperitoneum. Additional morbidities include abscess formation, obstruction, and migration to other organs with resulting injury. Cases of migration to the aorta, pericardium, coronary artery, lung, liver, portal vein, hepatoduodenal ligament, inferior vena cava, peritoneum, bladder, retroperitoneum, pancreas, kidney, ureter, perianal space, and hip have all been documented ${ }^{[7]}$.

Table 1. Percent perforation by all ingested foreign bodies based on anatomical location $(\mathrm{n}=236)$

\begin{tabular}{lll}
\hline Site of Perforation & Number of Patients & Percent Perforation \\
\hline Duodenum & 52 & $22.0 \%$ \\
Small Bowel & 94 & $39.8 \%$ \\
Cecum/Asc./Trans./Desc. Colon & 48 & $20.3 \%$ \\
Sigmoid & 13 & $5.5 \%$ \\
Rectum & 25 & $10.6 \%$ \\
Unknown & 4 & $1.7 \%$ \\
\hline
\end{tabular}

In analyzing percent perforation based on location, several limitations were identified. First, there exists a selection bias in this patient population. Cases reported likely represent a population of unusual presentations and severe morbidity. Second, most patients have no recollection of foreign body ingestion, thus the true rate of perforation remains unknown as many unreported cases may be asymptomatic. Finally, the variable reporting of precise location of perforation, led to ambiguity distinguishing between duodenal vs. jejunual vs. ileal perforations.

Several methods of foreign body removal have been described without consensus on the gold standard for treatment. According to Table 2, intervention for duodenal obstruction or perforation included endoscopy vs. laparoscopy vs. laparotomy. Duodenal perforation management frequently resulted in surgical intervention via exploratory laparotomy. Symptoms suggesting foreign body obstruction or perforation included abdominal pain, GI bleed, fever, leukocytosis, and hypotension. However, this case and others in literature reported successful removal of the foreign body by endoscopy without surgical intervention. Single-balloon enteroscopy and upper endoscopy have been described as successful techniques of toothpick removal ${ }^{[55,58]}$. Endoscopy appeared to be the most effective technique to identify and to remove foreign bodies from the GI tract of a stable patient without perforation into the peritoneum. Nevertheless, when endoscopic techniques fail, surgical intervention is indicated for treatment.

Table 2. Therapeutic options based on localization of foreign body

\begin{tabular}{ll}
\hline Treatment Options Based on Location of Foreign Body Obstruction \\
\hline Esophagus & Rigid or flexible endoscopy \\
Stomach & Endoscopy vs. laparoscopy vs. laparotomy with gastrotomy \\
Duodenum & Endoscopy vs. laparoscopy vs. laparotomy \\
Small bowel & Balloon enteroscopy vs. laparoscopy vs. laparotomy \\
Large Bowel & Laparoscopy vs. laparotomy \\
\hline
\end{tabular}

An algorithm for diagnosis and management of a suspected duodenal foreign body was developed from reviewing the literature (see Figure 3). First, risk factors of foreign body ingestion are assessed. These include bulimic females, elderly individuals with dentures, mental retardation, psychiatric illnesses, young children, and alcoholics. In a patient with these 
risk factors presenting with nausea, vomiting, anorexia, abdominal pain, bloating, epigastric tenderness, or fever require a thorough history and physical exam while obtaining appropriate laboratory data. Next, upright abdominal radiographs should be obtained. Evidence of peritoneal free air requires emergent laparotomy. Without signs of free air, additional imaging by abdominal CT scan with oral and IV contrast is next. If a foreign body is identified, endoscopy or surgery should follow depending on symptoms and anatomical location. However, without evidence of foreign body on CT scan, the patient should be assessed further by endoscopy if there exists a suspicion of foreign body ingestion.

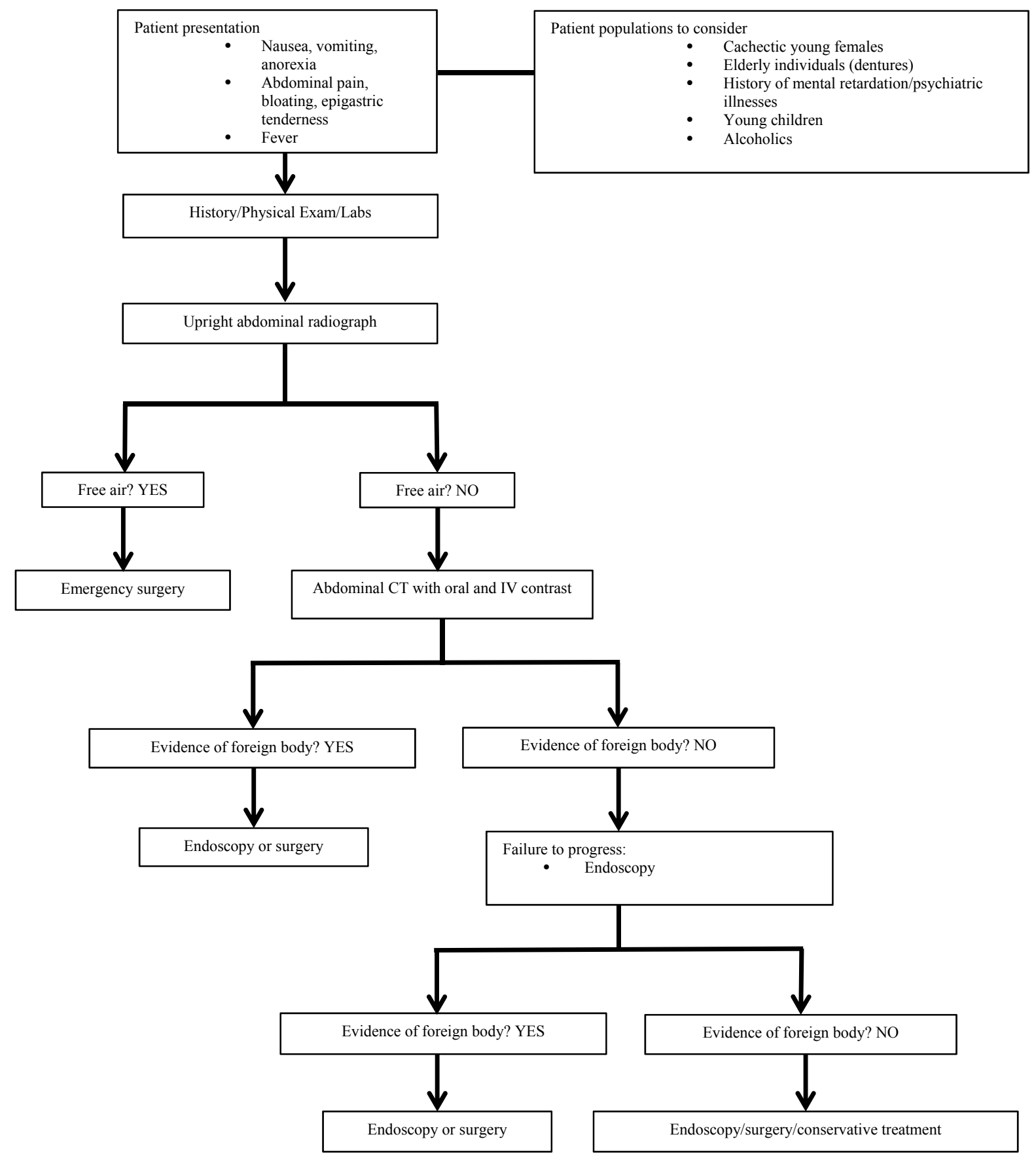

Figure 3. Diagnostic and therapeutic algorithm for suspected duodenal foreign body 
Foreign body ingestion of toothpicks poses a unique management challenge due to vague manifestations and the various approaches available for removal. In this case report, initial diagnosis of duodenal malignancy was made based on CT imaging findings. However, endoscopy identified a toothpick causing inflammation and perforation of the duodenum. As illustrated in this case, duodenal perforation can be managed with upper endoscopy alone, resulting in reduced procedural morbidity. The use of early endoscopy for diagnostic and therapeutic purposes could lead to more prompt diagnosis and a decrease in morbidity.

\section{Conclusion}

The difficulty in diagnosis and management of foreign body ingestion was exhibited in this case report and literature review. The clinical significance of ingested foreign bodies, especially toothpicks due to their sharp nature, should not be underestimated. Spontaneous passage of toothpicks through the GI tract is not uncommon. However, should perforation occur, the associated morbidity and mortality is high. Thus, prompt diagnosis and treatment are necessary for optimal outcomes.

\section{Acknowledgements}

There are no financial disclosures. The authors declare that they have no competing interests.

\section{References}

[1] Gore RM, Levine MS. Textbook of Gastrointestinal Radiology: Expert Consult. Elsevier Health Sciences. 2015.

[2] Berlin L. Duke Radiology Case Review: Imaging, Differential Diagnosis, and Discussion. JAMA. 2012; 307(20): 2199-2200. http://dx.doi.org/10.1001/jama.2012.5259

[3] Jayaraman MV, Mayo-Smith WW, Movson JS, et al. CT of the duodenum: an overlooked segment gets its due. RadioGraphics. 2001; 21: 147-160. PMid:11598254 http://dx.doi.org/10.1148/radiographics.21.supp1_1.g01oc01s147

[4] Madrona AP, Hernández JAF, Prats MC, et al. Intestinal perforation by foreign bodies. The European journal of surgery. 2000; 166(4); 307-309. PMid:10817327 http://dx.doi.org/10.1080/110241500750009140

[5] Chiu WY, Chen YJ, Cheng PC, et al. Early presentation of bowel perforation due to fish bone ingestion. QJM. 2014; 107(8): 679-80. PMid:24440924 http://dx.doi.org/10.1093/qjmed/hcu004

[6] Petrea S, Brezean I. Self harm through foreign bodies ingestion-rare cause of digestive perforation. J. Med. Life. 2014; 7(2): 246-53. PMid:25408734

[7] Steinbach C, Stockmann M, Jara M, et al. Accidentally ingested toothpicks causing severe gastrointestinal injury: a practical guideline for diagnosis and therapy based on 136 case reports. World J Surg. 2014; 38(2): 371-7. PMid:24166027 http://dx.doi.org/10.1007/s00268-013-2307-z

[8] Misra S, Jain V, Ahmad F, et al. Metallic sewing needle ingestion presenting as acute abdomen. Niger J Clin Pract. 2013; 16(4): 540-3. PMid:23974755 http://dx.doi.org/10.4103/1119-3077.116879

[9] Mark D, Ferris K, Martel G, et al. Radiological diagnosis of a small bowel perforation secondary to toothpick ingestion. BMJ Case Rep. 2013. http://dx.doi.org/10.1136/bcr-2013-009869

[10] Sahoo MR, Kumar A. Duodenal perforation caused by a bird feather. BMJ Case Rep. 2013. http://dx.doi.org/10.1136/bcr-2013-008635

[11] Ward MA, Tews MC. Small bowel perforation secondary to fish bone ingestion managed non-operatively. J Emerg Med. 2012; 43(5): e295-8. PMid:20692785 http://dx.doi.org/10.1016/j.jemermed.2010.05.039

[12] Kuo CC, Jen TK, Wen $\mathrm{CH}$, et al. Medical treatment for a fish bone-induced ileal micro-perforation: a case report. World J Gastroenterol. 2012; 18(41): 5994-8. PMid:23139620 http://dx.doi.org/10.3748/wjg.v18.i41.5994

[13] Centers for Disease Control and Prevention (CDC). Injuries from ingestion of wire bristles from grill-cleaning brushes-Providence, Rhode Island, March 2011-June 2012. MMWR Morb Mortal Wkly Rep. 2012; 61(26): 490-2. PMid:22763887

[14] Glick WA, Simo KA, Swan RZ, et al. Pyogenic hepatic abscess secondary to endolumenal perforation of an ingested foreign body. J Gastrointest Surg. 2012; 16(4): 885-7. PMid:21989581 http://dx.doi.org/10.1007/s11605-011-1711-7

[15] Alonso-Gomez S, Rubio-Gonzalez E, Donat-Garrido M, et al. Sigmoid colon perforation due to a foreign body ingestion. Rev Esp Enferm Dig. 2012; 104(2): 90-1. PMid:22372803 http://dx.doi.org/10.4321/S1130-01082012000200008 
[16] Suzuki Y, Mizuno M, Nakashima R, et al. A case of perforative peritonitis caused by a piece of bamboo in a patient on peritoneal dialysis. Clin Exp Nephrol. 2011; 15(6): 962-5. PMid:21879431 http://dx.doi.org/10.1007/s10157-011-0529-7

[17] Iusco DR, Jannaci M, Grassi A, et al. Unusual cause of right iliac fossa pain: sigmoid perforation due to ingested rabbit bone. Case report. G Chir. 2011; 32(10): 421-3. PMid:22018217

[18] Atila K, Guler S, Bora S, et al. An unusual cause of small bowel perforation: apricot pit. Ulus Travma Acil Cerrahi Derg. 2011; 17(3): 286-8. PMid:21935813 http://dx.doi.org/10.5505/tjtes.2011.71676

[19] McGregor DH, Liu X, Ulusarac O, et al. Colonic perforation resulting from ingested chicken bone revealing previously undiagnosed colonic adenocarcinoma: report of a case and review of literature. World J Surg Oncol. 2011; 9: 24.

[20] McGregor DH, Liu XY, Ulusarac O, et al. Colonic perforation resulting from ingested chicken bone revealing previously undiagnosed colonic adenocarcinoma: report of a case and review of literature. World J Surg Oncol. 2011; 9: 24. PMid:21333012 http://dx.doi.org/10.1186/1477-7819-9-24

[21] Guillen-Paredes MP, Liron-Ruiz R, Torralba-Martinez JA, et al. Intestinal perforation caused by incidental ingestion of a fish bone. Value of CT in the diagnosis. Rev Esp Enferm Dig. 2010; 102(9): 573-4. PMid:20883081 http://dx.doi.org/10.4321/S1130-01082010000900016

[22] Hur H, Song KY, Jung SE, et al. Laparoscopic removal of bone fragment causing localized peritonitis by intestinal perforation: a report of 2 cases. Surg Laparosc Endosc Percutan Tech. 2009; 19(6): e241-3. PMid:20027078 http://dx.doi.org/10.1097/SLE.0b013e3181bc37b3

[23] Lazaris AM, Tsapralis D, Patapis P, et al. Aortoiliac endograft-enteric fistula due to an ingested toothpick. J Vasc Surg. 2009; 50(3): 640-3. PMid:19540705 http://dx.doi.org/10.1016/j.jvs.2009.03.059

[24] Yagmur Y, Ozturk H, Ozturk H. Distal ileal perforation secondary to ingested foreign bodies. J Coll Physicians Surg Pak. 2009; 19(7): 452-3. PMid:19576157

[25] Kornprat P, Langner C, Mohadjer D, et al. Chicken-bone perforation of a sigmoid colon diverticulum into the right groin and subsequent phlegmonous inflammation of the abdominal wall. Wien Klin Wochenschr. 2009; 121(5-6): 220-2. PMid:19412753 http://dx.doi.org/10.1007/s00508-009-1157-7

[26] Dente M, Santi F, Solinas L, et al. Laparoscopic diagnosis and management of jejunal perforation resulting from accidental toothpick ingestion. Am Surg. 2009; 75: 178-179. PMid:19280815

[27] Malik AM. Small bowel perforations due to deliberate ingestion of injurious foreign bodies-a personal experience. J Ayub Med Coll Abbottabad. 2008; 20(2): 136-7. PMid:19385478

[28] Syrakos T, Zacharakis E, Antonitsis P, et al. Surgical intervention for gastrointestinal foreign bodies in adults: A case series. Medical principles and practice: International Journal of Kuwait University. 2008; 17(4): 276-279. PMid:18523393 http://dx.doi.org/10.1159/000129605

[29] Lee TH, Lee SH, Park JH, et al. Endoscopic management of duodenal perforation secondary to ingestion of an uncommon foreign body. Gastrointest Endosc. 2008; 67(4): 729-31. PMid:18279871 http://dx.doi.org/10.1016/j.gie.2007.10.056

[30] Nigri GR, Di Giulio E, Di Nardo R, et al. Duodenal perforation and right hydronephrosis due to toothpick ingestion. J Emerg Med. 2008; 34(1): 55-7. http://dx.doi.org/10.1016/j.jemermed.2006.11.014

[31] Lee MR, Hwang Y, Kim JH. A case of colohepatic penetration by a swallowed toothbrush. World J Gastroenterol. 2006; 12(15): 2464-5. PMid:16688846

[32] Khan AS, Ali U. Ingestion of metallic rods and needles. J Coll Physicians Surg Pak. 2006; 16(4): 305-6. PMid:16624202

[33] Goh BK, Chow PK, Quah HM, et al. Perforation of the gastrointestinal tract secondary to ingestion of foreign bodies. World J Surg. 2006; 30: 372-7. PMid:16479337 http://dx.doi.org/10.1007/s00268-005-0490-2

[34] Bhatia R, Deane AJ, Landham P, et al. An unusual case of bowel perforation due to fish fin ingestion. Int J Clin Pract. 2006; 60(2): 229-31. PMid:16451298 http://dx.doi.org/10.1111/j.1742-1241.2006.00610.x

[35] Wichmann MW, Huttl TP, Billing A, et al. Laparoscopic management of a small bowel perforation caused by a toothpick. Surg Endosc. 2004; 18(4): 717-8. PMid:15214371 http://dx.doi.org/10.1007/s00464-003-4267-0

[36] Leelouch N, Ayoub N, Bruneel F, et al. Thigh Cellulitis caused by toothpick ingestion. Intensive Care Med. 2003; 29 : 662-3.

[37] Li SF, Ender K. Toothpic injury mimicking renal colic: Case report and systematic review. J Emerg Med. 2002; 23 : 35-8. http://dx.doi.org/10.1016/S0736-4679(02)00458-4

[38] Gupta V, Manikyam SR, Gupta R, et al. Pelvic abscess after ingestion of blister-wrapped tablet. Am J Gastroenterol. 2002; 97(8): 2142-3. PMid:12190196 http://dx.doi.org/10.1111/j.1572-0241.2002.05940.x

[39] Beer TW. Fatalities from bread tag ingestion. Med J. 2002; 176: 506.

[40] Memon MA, Macafee D, Rattan H. Accidental ingestion of cotton bud stick during alcohol intoxication: an unusual cause of caecal perforation. Ir Med J. 2002; 95(1): 19-20. PMid:11928784 
[41] Newell KJ, Taylor B, Walton JC, et al. Plastic bread-bag clips in the gastrointestinal tract: report of 5 cases and review of the literature. CMAJ. 2000; 162(4): 527-9. PMid:10701390

[42] Russell R, Lucas A, Johnson J, et al. Extraction of esophageal foreign bodies in children: rigid versus flexible endoscopy. Pediatr Surg Int. 2014; 30(4): 417-22. PMid:24549805 http://dx.doi.org/10.1007/s00383-014-3481-2

[43] Rodríguez H, Passali GC, Gregori D, et al. Management of foreign bodies in the airway and oesophagus. Int J Pediatr Otorhinolaryngol. 2012; 76(Suppl 1): S84-91. PMid:22365376 http://dx.doi.org/10.1016/j.ijporl.2012.02.010

[44] Nirasawa Y, Mori T, Ito Y, et al. Laparoscopic removal of a large gastric trichobezoar. J Pediatr Surg. 1998; $33(4)$ : $663-665$. http://dx.doi.org/10.1016/S0022-3468(98)90342-6

[45] Sharma D, Srivastava M, Babu R, et al. Laparoscopic treatment of gastric bezoar. JSLS. 2010; 14(2): 263-7. PMid:20932381 http://dx.doi.org/10.4293/108680810X12785289144566

[46] Rabie ME, Arishi AR, Khan A, et al. Rapunzel syndrome: the unsuspected culprit. World J Gastroenterol. 2008; 14(7): $1141-1143$. PMid:18286701 http://dx.doi.org/10.3748/wjg.14.1141

[47] Islam SR, Islam EA, Hodges D, et al. Endoscopic removal of multiple duodenum foreign bodies: An unusual occurrence. World J Gastrointest Endosc. 2010; 2(5): 186-9. PMid:21160746

[48] Henderson CT, Engel J, Schlesinger P. Foreign body ingestion: review and suggested guidelines for management. Endoscopy. 1987; 19(2): 68-71. PMid:3552641 http://dx.doi.org/10.1055/s-2007-1018238

[49] Ragazzi M, Delcò F, Rodoni-Cassis P, et al. Toothpick ingestion causing duodenal perforation. Pediatr Emerg Care. 2010; 26(7): 506-7. PMid:20622631 http://dx.doi.org/10.1097/PEC.0b013e3181e5bf85

[50] Chao HH, Chao TC. Perforation of the duodenum by an ingested toothbrush. World J Gastroenterol. $2008 ; 14(27): 4410-2$. http://dx.doi.org/10.3748/wjg.14.4410

[51] Kim MJ, Seo JM, Lee Y, et al. An unusual cause of duodenal perforation due to a lollipop stick. Korean J Pediatr. 2013; 56(4): 182-5. PMid:23646057 http://dx.doi.org/10.3345/kjp.2013.56.4.182

[52] Gray DM, To K, Wang JS. Toothpick perforation of the small bowel. Clin Gastroenterol Hepatol. 2011; 9(11): A26. PMid:21699804 http://dx.doi.org/10.1016/j.cgh.2011.05.013

[53] Sethi S, Cohen J, Thaker AM, et al. Prior Capsule Endoscopy Improves the Diagnostic and Therapeutic Yield of Single-Balloon Enteroscopy. Dig Dis Sci. 2014. http://dx.doi.org/10.1007/s10620-014-3178-3

[54] DeMuro JP, Adamo A. Sigmoid colon perforation from an impacted toothpick and an occult colonic malignancy. Am Surg. 2013; 79(8): E273-4. PMid:23896234

[55] Terrace JD, Samuel J, Robertson JH, et al. Chicken or the leg: Sigmoid colon perforation by ingested poultry fibula proximal to an occult malignancy. Int J Surg Case Rep. 2013; 4(11): 945-7. PMid:24060703 http://dx.doi.org/10.1016/j.ijscr.2013.08.001

[56] Boškoski I, Tringali A, Landi R. Endoscopic retrieval of a duodenal perforating teaspoon. World J Gastrointest Endosc. 2013; 16; 5(4): 186-188.

[57] Robert B, Bartoli E, Fumery M, et al. Duodenal perforation due to toothpick perforation, an uncommon cause of chronic abdominal pain. Endoscopy. 2012; 44(S02): E27-E28. http://dx.doi.org/10.1055/s-0031-1291507

[58] Sealock RJ, Sabounchi S, Graham DY. Toothpick perforation of the intestines presenting as recurrent abdominal pain: possible roles of abdominal ultrasound and MRI. Clinical Medicine Insights: Case Reports. 2013; 6: 131-135.

http://dx.doi.org/10.4137/ccrep.s11486

[59] Hsieh MJ, Lee TC, Tseng CH, et al. Duodenum-penetrating toothpick with liver abscess: removal with single-balloon enteroscopy. Endoscopy. 2011; 43(Suppl 2) UCTN: E11-E12. 